\title{
Acolhimento como ativismo: ações de um coletivo bissexual na criação de espaços "monodissidentes"*
}

\author{
Welcoming as activism: actions of a bisexual collective to create \\ "monodissident" spaces
}

\section{La acogida como activismo: acciones de un colectivo bisexual en la creación de espacios "monodisidentes"}

Recebido em 29-08-2020

Modificado em 20-09-2020

Aceito para publicação em 30-10-2020

\section{Helena Motta Monaco}

ORCID: 0000-0001-8505-8487

Mestra em Antropologia Social pela Universidade Federal de Santa Catarina. Integrante do Núcleo de Antropologia do Contemporâneo. E-mail: helenamonaco@gmail.com

\section{Resumo}

Este artigo tem como objeto a atuação de um coletivo bissexual da cidade de São Paulo, tendo por objetivo explorar a bissexualidade enquanto organização política, em especial no que diz respeito à criação de espaços de acolhimento. A pesquisa foi realizada por meio de entrevistas semiestruturadas com doze ativistas, além de observação participante em uma atividade presencial e análise de documentos publicados pelo coletivo. Foi constatado que o coletivo adota uma política de biolegitimidade na medida em que reivindica direitos às pessoas bissexuais, afirmando a existência de um sofrimento que teria origem na bifobia que as vitimiza. Por sua vez, nas narrativas individuais, os interlocutores utilizam a noção de "descoberta da bissexualidade", na qual encontrar acolhimento em uma comunidade bissexual aparece como um fator fundamental para a construção de uma identidade bissexual e para o combate ao sofrimento psíquico.

Palavras-chave: Bissexualidade; Monodissidência; Ativismo; Movimentos LGBTQIA+.

* O presente trabalho foi realizado com apoio da Coordenação de Aperfeiçoamento de Pessoal de Nível Superior - Brasil (CAPES) - Código de Financiamento 001 


\section{Introdução}

A bissexualidade tem sido um motivo de grandes controvérsias ao longo dos anos, tanto no âmbito da pesquisa acadêmica quanto dos movimentos sociais. Neste artigo, exploro a bissexualidade como organização política, a partir da atuação de um coletivo de ativismo bissexual na cidade de São Paulo, que chamarei aqui de "coletivo B"1. O objetivo deste trabalho é apresentar a ideia de acolhimento como uma das principais formas de atuação e ativismo empregadas por esse coletivo. Aqui, a noção de acolhimento diz respeito a iniciativas que, mais do que reivindicar direitos ou políticas públicas, se concentram primordialmente em criar espaços seguros de convivência e trocas entre pessoas bissexuais. Essas iniciativas buscam construir uma espécie de comunidade bissexual e evidenciam a valorização de uma sociabilidade bissexual por parte dos ativistas.

Alguns dos espaços de ativismo bissexual de maior abrangência no Brasil são aqueles organizados e gerenciados por organizações autodenominadas coletivos. Organizações desse tipo ganharam força nos anos 2010, especialmente a partir de 2013, com as chamadas Jornadas de Junho (Perez, 2019). A recente literatura tem caracterizado os coletivos como organizações societárias baseadas nos princípios de horizontalidade, autonomia, colaborativismo, bem como os tem percebido como experiências mais fluídas e dialógicas quando comparados às estruturas hierárquicas e/ou formais comumente presentes nas organizações partidárias e em certas organizações de movimento social com maior grau de formalização (Bordt, 1997; Gohn, 2017; Lima, 2018; Maia, 2013; Perez, 2019; Perez; Silva Filho, 2017). Vale também destacar que recentes pesquisas têm demonstrado que os coletivos são frequentemente compostos por jovens que se se autodenominam ativistas e que se identificam com os ideários anarquistas e libertários (Gohn, 2017).

Partindo dessa concepção de coletivos, neste trabalho, analiso as ações do coletivo B. Trata-se de um coletivo que se declara "monodissidente", ou seja, fundado por e para pessoas com sexualidade e/ou afetividade dissidente da "monossexualidade", entendida como atração por apenas um gênero (como são os casos da heterossexualidade e da homossexualidade). $O$ referido coletivo surgiu em 2010, em São Paulo, com o objetivo de articular redes de

\footnotetext{
${ }^{1}$ Utilizo pseudônimos para me referir tanto ao coletivo quanto aos sujeitos da pesquisa individualmente, de modo a preservar suas identidades. A escolha pelo anonimato do coletivo se justifica, pois nomeá-lo levaria à identificação de sujeitos que são reconhecidos por seus pares como parte dele e que me revelaram aspectos sensíveis de suas vidas durante as entrevistas. Além disso, esta escolha deve-se à necessidade de preservar os espaços criados pelo coletivo, bem como seus membros, de possíveis perseguições ou ataques, em especial nas mídias digitais.
} 
bissexuais local, nacional e internacionalmente por meio do compartilhamento de informações a respeito da bissexualidade. Sua criação parte da insatisfação de ativistas bissexuais com a falta de representação da bissexualidade nos movimentos LGBTQIA+ (Lésbicas, Gays, Bissexuais, Transexuais, Transgêneros, Travestis Queer, Intersexuais, Assexuais e outras identidades), visando reverter essa invisibilidade. Originalmente, os ativistas organizavam um blog, criado para disponibilizar traduções de material estrangeiro sobre bissexualidade. Em 2010, a criadora do blog se juntou a outros ativistas, os quais criaram um grupo de comunicação digital por onde organizaram algumas reuniões e atos próximos ao Dia da Visibilidade Bissexual (23 de setembro). Pouco depois, os encontros foram descontinuados e, após um período de cerca de dois anos sem atividades, os ativistas se mobilizaram novamente, criando um grupo na rede social digital Facebook. Começaram, então, a realizar outras atividades e participações em eventos, mas foi apenas no final de 2017 que o coletivo começou a organizar uma atividade regular própria, a Roda de Validação de Experiências Bissexuais.

Hoje, o grupo do Facebook conta com mais de quatro mil membros. Maria Leão (2018) chama atenção para a importância desse grupo que, de acordo com ativistas entrevistadas por ela, tem papel fundamental na formação política de bissexuais e na organização de atividades e grupos de militância locais, pois facilita o encontro de pessoas bi. Atualmente, o coletivo se identifica com o ativismo e militância bissexual, promove eventos, realiza palestras, ativismo digital e produz material informativo, além de participar de atos como a Parada do Orgulho LGBTQIA+, Marcha das Vadias e Caminhada de Lésbicas e Bissexuais de São Paulo.

Um Manifesto publicado em janeiro de 2019 pelo coletivo afirma que ele assume uma postura antifascista e que a maioria de seus integrantes é inclinada ao anarquismo, demonstrando um exemplo das influências anarquistas em organizações autodenominadas coletivos, já identificadas por Gohn (2017). Uma das ativistas, inclusive, afirmou em entrevista que os moderadores são "bastante à esquerda, bastante de movimento, inclusive de construção de base, pra além dessas questões políticas partidárias", evidenciando o caráter independente e apartidário aparentemente típico desse tipo de organização (Maia, 2013).

A pesquisa foi realizada no período de janeiro a abril de 2019, com aproximação inicial por meio das mídias digitais do coletivo, mais especificamente da sua página no Facebook. A partir dela, entrei em contato com representantes e, posteriormente, outros participantes do coletivo. Realizei entrevistas semiestruturadas com 12 membros e 
participantes, além de fazer observação de suas redes sociais e participar de uma Roda de Validação promovida pelo coletivo.

As entrevistas tiveram caráter interativo, de acordo com o método compreensivo descrito por Jean-Claude Kaufmann (2013), segundo o qual a condução de entrevistas na antropologia deve buscar romper com o tom hierárquico do questionário, que requer respostas breves e diretas, desenvolvendo-se, ao contrário, com um tom mais próximo ao de um diálogo entre os participantes: entrevistadora e entrevistado. O principal objetivo das entrevistas era identificar, de um lado, aspectos relativos à construção da subjetividade bissexual e, de outro, as estratégias e demandas políticas do coletivo B. Por esse motivo, o roteiro de entrevistas foi dividido em dois blocos de questões norteadoras: questões sobre a subjetividade do entrevistado e questões sobre o coletivo B. O primeiro bloco centrava-se principalmente nos processos de construção de um "eu" bissexual, buscando compreender como o entrevistado passou a se identificar como bissexual. O segundo bloco dizia respeito à atuação do coletivo, suas formas de organização e principais objetivos.

Para romper com o formato hierárquico e fechado do questionário, as questões foram formuladas de forma ampla e aberta, de modo a estimular a fala e a produção de narrativas por parte dos entrevistados. Ademais, o roteiro foi utilizado apenas como referência e direcionamento - para dar conta dos interesses da pesquisa durante a realização das entrevistas -, mas não foi seguido de forma estrita e linear. Ao contrário, busquei trazer as temáticas de interesse a partir da fala dos entrevistados, frequentemente extrapolando em muito as perguntas que havia formulado inicialmente, o que permitiu uma visão mais ampla e rica dos temas de interesse dos próprios sujeitos da pesquisa. Por esse motivo, as entrevistas foram muito diferentes umas das outras, já que detinham a atenção nos assuntos que pareciam mais relevantes para cada uma das pessoas entrevistadas, mas, ainda assim, apresentaram pontos de convergência.

As idades das pessoas entrevistadas variam de 20 a 34 anos, com uma média de 29. Em sua maioria, são de classe média e escolarizadas: todas têm ensino superior completo ou estavam cursando no momento da entrevista. Muitas moram com a família de origem - mãe e pai (ou apenas a mãe) e, às vezes, irmãos e avós - e outras sozinhas, com companheiros ou, menos frequentemente, amigos. Apenas uma delas tem filho e duas são divorciadas. Os sujeitos utilizam uma forma de classificação da sexualidade corrente no ativismo bi que extrapola a fórmula heterossexual/bissexual/homossexual, que abordarei na primeira seção deste artigo. Assim, oito se identificaram como "bi" ou "bissexuais" e quatro como "pan", "pansexuais" ou "panromânticas". 
Além desta introdução, o artigo se divide em três seções. A primeira explora as categorias de classificação da sexualidade e da afetividade utilizadas pelo coletivo B e no ativismo bissexual de forma mais ampla, bem como as implicações no uso de uma categoria identitária como agregadora, que foi substituída, pelo coletivo, pela categoria "monodissidência". Na segunda seção, apresento um panorama histórico dos movimentos bissexuais internacionais, com foco nos mais influentes, isto é, nos chamados movimentos bissexuais hegemônicos localizados principalmente nos Estados Unidos. Em seguida, apresento os percursos do movimento bissexual brasileiro, de modo a localizar a emergência e atuação do coletivo B. Finalmente, na última seção, exploro mais detalhadamente a atuação do coletivo e suas iniciativas voltadas ao acolhimento de pessoas bissexuais, que se fundamentam na identificação de um grande índice de adoecimento mental da população bissexual e na consequente necessidade de lhe oferecer apoio psicológico.

\section{Formas de classificação da sexualidade}

No contexto do ativismo bissexual, a bissexualidade não aparece unicamente como categoria identitária, mas também como termo agregador que abarca outras identidades, práticas e desejos sexuais ou afetivos. Entre as pessoas entrevistadas, as únicas identidades que apareceram foram "bissexual" e "pansexual", além de suas derivações (como "bi", "pan", "panromântico", entre outras). Aqui, a bissexualidade é entendida como atração por mais de um gênero, enquanto a pansexualidade é entendida como atração sexual ou romântica por pessoas de todos os gêneros e/ou atração independente do gênero ${ }^{2}$.

Nessa forma de classificação, há ainda uma divisão entre o que seria "sexualidade" e "romanticidade" nos entendimentos sobre bi e pansexualidade. A dimensão sexual da atração, para os sujeitos da pesquisa, diz respeito a uma atração genitalizada, relacionada à excitação erótica, ao passo que a dimensão identificada como romântica diz respeito a aspectos afetivos e emocionais. Assim, alguns sujeitos da pesquisa se identificam como "panromânticos", entendendo que sua atração independe do gênero e é "romântica" (afetiva), e não "sexual" (erótica). Isso ocorre principalmente no caso de pessoas que se identificaram como assexuais, ou seja, que declararam não sentir atração do tipo "sexual”, embora possam sentir atração

\footnotetext{
${ }^{2}$ Essas caracterizações partem do pressuposto, defendido pelo coletivo $\mathrm{B}$, de que não há apenas dois gêneros e, portanto, a bissexualidade não se resume à atração por apenas dois gêneros, ou apenas homens e mulheres, podendo incluir, por exemplo, pessoas de gênero não-binário.
} 
"romântica". Outras pessoas utilizam apenas o prefixo "pan" isoladamente para falar da sua sexualidade e/ou afetividade - sem necessariamente fazer essa distinção.

Todas as pessoas que se identificaram como $\operatorname{pan}^{3}$ no contexto da pesquisa, entretanto, consideram "bissexual" um termo guarda-chuva, que inclui bissexuais, pansexuais e polissexuais. Shiri Eisner (2013) explica que o termo bissexual, usado como guarda-chuva, representa um espectro de identidades. Esse espectro inclui as identidades bissexual ${ }^{4}$, pansexual, polissexual, queer, sexualidade fluida, homoflexível, heteroflexível, multissexual, entre outras. Por esse motivo, utilizo aqui a categoria bissexualidade como agregadora, incluindo as demais identidades sexuais abarcadas por ela na classificação dos sujeitos da pesquisa. Apesar disso, é importante destacar que o uso da categoria bissexual como guardachuva não é consenso entre os ativistas bissexuais e pansexuais em outros contextos. Ao contrário, esse uso frequentemente é alvo de disputas e discussões, sobretudo no que diz respeito à visibilidade de pessoas que se identificam como pansexuais e não se veem representadas na palavra "bissexual" como agregadora.

Entretanto, no contexto estudado, não foi percebida uma diferenciação estrita entre cada um dos termos que se encontram sob o guarda-chuva da bissexualidade. Ao invés disso, cada pessoa definiu sua bissexualidade ou pansexualidade a partir da própria experiência. Em geral, considera-se que a diferença entre os termos diz respeito mais a uma preferência pessoal na forma de identificação do que a uma diferença fundamental entre duas sexualidades. Nesse sentido, a distinção entre bissexualidade e pansexualidade não é essencializada no discurso dos interlocutores.

A multiplicidade de formas de identificação pessoal dos integrantes do coletivo reflete na identificação do próprio coletivo, que se coloca como "monodissidente". Aqui, a ideia de monodissidência diz respeito à noção de dissidência da monossexualidade, como projeto de unificação política de bis e pans. Para Leão (2018), o conceito de dissidência "evidencia a ideia de bissexualidade como uma resistência politizada às estruturas vigentes da sexualidade" (Leão, 2018:28). A categoria monodissidência reconhece o lugar de "outro" da bissexualidade em relação à monossexualidade e à oposição hétero/homossexual. Trata-se de um projeto de unificação dos movimentos bi e pan que inclui diferenças por não se tratar de uma categoria identitária, mas de um termo que agrega diferentes formas de identificar e vivenciar a sexualidade como parte de uma mesma mobilização política.

\footnotetext{
${ }^{3}$ Utilizo o prefixo "pan" isolado para me referir a todos os sujeitos de pesquisa que se identificam como pansexuais, panromânticos e pan.

${ }^{4}$ Aqui a categoria bissexual aparece não como agregadora, mas como identidade política específica, incluída no "guarda-chuva bissexual" mais amplo.
} 
Com o uso dessa categoria, o coletivo B se diferencia tanto da heterossexualidade quanto da homossexualidade, identificadas simultaneamente como "monossexuais", ao passo que almeja abranger experiências que extrapolam a bissexualidade. Nesse sentido, a monodissidência parece funcionar de forma semelhante ao queer, conforme descrito por Amber Ault (2002). Para a autora, o queer evoca um senso de multiplicidade sexual, mas, ao mesmo tempo, possui a capacidade homogeneizante de eliminar diferenças, construindo um mundo binário constituído de queers e não-queers. Por sua vez, a ideia de monodissidência reconhece uma multiplicidade de sexualidades não-monossexuais, no entanto, cria outra oposição binária: monossexuais/monodissidentes. Não obstante, essa oposição torna-se permeável com a inclusão da chamada atração romântica, permitindo o reconhecimento de formas distintas de desejo e inúmeras configurações identitárias em um mesmo movimento.

Um dos ativistas entrevistados, David, identifica no termo monodissidência uma forma de não excluir as diferenças dentro do chamado espectro bissexual:

\footnotetext{
A gente acredita, eu acredito no termo monodissidente porque ele não exclui ninguém. Então independente se você é bi, pan, poli, multi, heteroflexível, homoflexível, em monodissidente você vai tá incluído, é uma palavra que engloba todas essas identidades. Mesmo que não explique em completude com sua especificidade, mas ela traz a ideia de que todo mundo tá junto (Entrevista com David, 2019).
}

Ao incluir as diferentes formas de identificação das pessoas que se atraem por mais de um gênero e, simultaneamente, reconhecer diferentes tipos de atração - sexual e romântica o conceito de monodissidência parece figurar uma tentativa de desvio de políticas identitárias. Não obstante, ele levanta outros dilemas estratégicos para o movimento bissexual. Para o ativista Shang, muitas das dificuldades de mobilização e organização política de bissexuais e monodissidentes vêm da dificuldade de se reconhecer e se identificar como bissexual, em decorrência da invisibilidade. Por esse motivo, haveria a necessidade de unificação do movimento, que antes era feita pelo uso da bissexualidade como guarda-chuva. Porém, haveria também uma necessidade de não fechar o movimento em uma identidade única, para não excluir a diversidade, o que dificulta a reivindicação, por exemplo, de visibilidade. Aqui, a dificuldade de unificação do movimento bissexual brasileiro é vista como uma falta de organização. Por sua vez, uma eventual organização nesse sentido poderia ser limitadora e excludente, pois fechar o movimento em uma identidade única limitaria sua diversidade.

Assim, o coletivo B aposta na ideia de monodissidência como uma forma de, simultaneamente, unificar o movimento e acolher pessoas de diferentes identidades e práticas sexuais que sofrem os efeitos do que chama de monossexismo, ou seja, a ideia de que todos 
são ou deveriam ser monossexuais. O uso dessa categoria demonstra, pois, um compromisso do coletivo com os ideais coletivistas de horizontalidade e igualdade entre os participantes, conforme descritos por Bordt (1997), Maia (2013) e Lima (2018), uma vez que não elege uma identidade única - bissexual - como protagonista de seu ativismo, abrindo espaço para uma multiplicidade de identificações e expressões da sexualidade.

\section{Um breve panorama dos movimentos bissexuais}

A organização política bissexual emerge dos movimentos gays, lésbicos e feministas dos anos 1970, fundamentada na insatisfação com políticas identitárias (Callis, 2009). Nessa década começam a surgir organizações bissexuais em alguns lugares do mundo. De acordo a organização bissexual estadunidense BiNet USA, nesse período são criados diversos grupos de apoio nos Estados Unidos, como o National Bisexual Liberation Group (em 1972), o Bi Forum (1975) e o San Francisco Bisexual Center (1976). Esses grupos frequentemente tinham predominância masculina, mas, nos anos 1980, mulheres com experiências em movimentos lésbicos e feministas passam a tomar a frente. Catherine Deschamps (2008) afirma que, nessa década, novas organizações bissexuais passam a ser encabeçadas por mulheres na América do Norte, Alemanha, Austrália e outros países.

No final dos anos 1980, muitos grupos de bissexuais norte-americanos reivindicavam a inclusão do termo bissexual em nomes de organizações, conferências e paradas do orgulho. Nos anos 1990, a comunidade política bissexual se expande e se consolida, com coalizões nacionais e internacionais. Aumenta também o número de publicações, tanto de revistas e boletins quanto de coletâneas e livros em geral que têm a bissexualidade como tema principal.

Em 1999 foi criado o Dia da Visibilidade Bissexual, 23 de setembro, pelos ativistas da BiNet USA Wendy Curry, Michael Page e Gigi Raven Wilbur (Leão, 2018). Esta data marca ações importantes de coletivos e ativistas bissexuais por todo o mundo até a atualidade. Por esse motivo, muitas das iniciativas lançadas pelo coletivo B são realizadas ou intensificadas no mês de setembro, como forma de tornar a bissexualidade visível e trazer à tona suas demandas específicas.

No Brasil, a questão da bissexualidade aparece mais fortemente nos anos 1980, acompanhando a epidemia de HIV/AIDS (Mação, 2017), como ocorreu em diversos países 5 .

\footnotetext{
${ }^{5}$ Storr (2002) mostra que nos anos 1980 a bissexualidade foi alvo de estudos por parte de epidemiologistas, devido a uma preocupação de que homens com comportamento bissexual agiriam como uma ponte de infecção a chamada "ponte bissexual" - espalhando HIV de comunidades gays para a população heterossexual. No centro
} 
Num primeiro momento, a bissexualidade aparece, portanto, como uma figura ameaçadora que representa uma espécie de risco biológico relacionado à epidemia. É nesse contexto que o sexo da parceria sexual se torna mais significativo do que a ideia de ser ativo ou passivo numa relação sexual, especialmente entre homens. Fernando Seffner (2003) argumenta que é a partir da AIDS que a bissexualidade masculina se torna mais visível e comentada no Brasil tanto negativamente, caracterizando homens bissexuais como culpados pela transmissão do HIV, quanto positivamente, como uma sexualidade futurista e moderna.

Não obstante, Fernando Seffner (2003) mostra que a bissexualidade não conquistou, aqui, um reconhecimento enquanto identidade, pois não havia uma política de identidade bissexual até então. Havia uma assimetria muito grande entre as identidades homossexuais e bissexuais no Brasil, porque o movimento homossexual teria constituído uma "cultura da homossexualidade", com espaços reconhecidos como homossexuais, serviços oferecidos a esse público, figuras públicas e ativistas que falam em nome dos homossexuais. No caso da bissexualidade, isso não ocorreu.

A própria consolidação das categorias identitárias "gay" e "lésbica" parece ter dificultado a entrada e permanência de bissexuais nesses movimentos sociais. De fato, para Camila Cavalcanti (2007), a busca por um elemento definidor, que fez emergirem as identidades gays e lésbicas, colaborou para a disseminação de estereótipos, reforçando estratégias reguladoras, como no caso da polarização homossexual/heterossexual. Isso se materializa nas controvérsias e disputas envolvendo bissexuais e movimentos LGBTQIA+. Em sua pesquisa sobre o grupo CORSA (Cidadania, Orgulho, Respeito, Solidariedade e Amor), criado em 1995 em São Paulo e identificado, na época, como um grupo pela emancipação das minorias sociais, Facchini (2002) identificou que as pessoas que se diziam bissexuais ou mencionavam práticas sexuais com pessoas de diferentes gêneros eram alvo de estranhamento e comentários negativos, incluindo brincadeiras maldosas por parte de lideranças do grupo. Segundo Facchini (2002), a bissexualidade era associada ao "enrustimento", fato que ela relaciona com o modelo de militância do movimento homossexual brasileiro, muito pautado na afirmação de identidades. Isso também ocorreu no Grupo Somos, identificado como o primeiro grupo de defesa dos direitos homossexuais no Brasil, onde a bissexualidade era criticada ou vista como uma desculpa para não se assumir homossexual por completo. Apesar disso, a prática bissexual era por vezes glorificada como

dessa preocupação estava o estereótipo do homem bissexual enrustido, que faz sexo desprotegido e casual com outros homens, contrai HIV e o transmite para sua esposa. No caso das mulheres bissexuais, a equação se inverte: as mulheres bi foram imaginadas como responsáveis por levar doenças para as comunidades lésbicas a partir do contato com homens heterossexuais. 
uma subversão de todas as regras e como um ideal de futuro utópico - de forma semelhante ao que ocorreu nas representações da bissexualidade na mídia, como uma sexualidade do futuro (Seffner, 2003). Embora caracterizada como positiva, a bissexualidade "futurista" ou como utopia reproduz o que Angelides (2001) identificou como um apagamento da bissexualidade no tempo presente.

Outras pesquisadoras, como Camila Dias Cavalcanti (2007) e Elizabeth Lewis (2012), identificam questões semelhantes mais recentes. Cavalcanti (2010) mostra que pessoas que se identificavam como bissexuais dentro de espaços de ativismo LGBT eram consideradas indecisas, promíscuas e homossexuais não assumidas. Ademais, em pesquisa com ativistas bissexuais em uma associação de conscientização e ativismo LGBT, Lewis (2012) constatou que havia um policiamento das práticas, identidades ou desejos bissexuais no interior do grupo. Lewis (2012) argumenta que, dentro dos movimentos LGBT, opera uma "matriz homonormativa", que exige a expressão de desejo por pessoas do mesmo sexo/gênero, contribuindo para a marginalização de pessoas bissexuais e demais agentes que não necessariamente correspondem a esta norma.

Em minha pesquisa, a rejeição a bissexuais e à bissexualidade no interior de movimentos LGBTQIA+ apareceu em relatos sobre a participação e organização da Parada do Orgulho LGBTQIA+ de São Paulo. Em 2018, a Parada teve seu primeiro bloco oficial específico para pessoas bissexuais, pansexuais e polissexuais, a partir da criação de um grupo de trabalho para organizá-lo, o GT BiPanPoli. O GT incluiu pessoas ligadas ao coletivo B, a outros coletivos, e ativistas independentes. Com sua criação, integrantes do GT BiPanPoli entraram em conflito com a Associação da Parada do Orgulho LGBTQIA+ de São Paulo (APOGLBT-SP), pois haviam solicitado um trio elétrico para o bloco BiPanPoli, que a associação recusou, dando prioridade para ceder o trio a outros blocos. Os ativistas contam que em 2018 o bloco foi aberto "à força": a corda para isolá-lo foi comprada pelos próprios integrantes do GT, não havia pessoal para segurá-la e não foi disponibilizado trio elétrico. Um deles relata a recusa da APOGLBT-SP em apoiar o bloco:

Foi uma briga feia, o pessoal tava realmente tentando e eles recusaram. Tipo, a gente não vai ajudar vocês. Se vocês quiserem fazer o rolê de vocês, vocês fazem. Tanto que durante todo o percurso da parada, os outros blocos têm trio, têm água que é dada pela prefeitura, têm cordeiros pra poder ficar segurando o trio, etc. Os cordeiros do nosso bloco fomos nós (Entrevista com Shang, 2019).

Em 2019, a APOGLBT disponibilizou um formulário de inscrição para participação nos GTs e foi formado novamente um GT BiPanPoli. No período de realização das 
entrevistas, os ativistas estavam se organizando para tentar conseguir um trio elétrico para esse ano. A Parada de 2019 foi realizada em 23 de junho e, mais uma vez, o bloco BiPanPoli não contou com carro de som ou apoio oficial para o pagamento de materiais e pessoal para o isolamento do bloco. Essa relação com a APOGLBT é vista pelos ativistas como um descaso que reflete uma situação maior de conflitos no interior de movimentos LGBTQIA+. Nas palavras do ativista Renato: “a comunidade LGBT é uma farsa. Não existe comunidade LGBT. Existe um monte de gente LGBT que vai pros mesmos espaços às vezes. Não existe uma comunidade LGBT".

A pouca aceitação da bissexualidade nesses espaços parece ter feito com que ativistas bissexuais criassem um espaço próprio. Conforme aponta Maria Leão (2018), a participação de bissexuais em movimentos sociais no Brasil é pulverizada, tornando difícil identificar espaços onde a bissexualidade aparece como temática central de discussões políticas. Isso pode ter relação com a falta de uma identidade política bissexual consolidada, que dificulta sua inserção em movimentos LGBTQIA+, que são pautados na afirmação de identidades sexuais distintas. Entretanto, uma série de espaços marcadamente bissexuais começaram a se desenvolver nos anos 2000, especialmente a partir dos conflitos de bissexuais envolvidos com movimentos LGBTQIA+. A partir dos anos 2010, essas organizações bissexuais tomam a forma de coletivos, que promovem palestras e debates em diferentes regiões do Brasil, participam de atos feministas e/ou relacionados a direitos LGBTQIA+. Parte desses grupos e coletivos é criada em resposta a situações de apagamento e bifobia (Domínguez Ruiz, 2017) dentro de movimentos LGBTQIA+ - não como movimentos separados, mas como formas de reivindicar espaços dentro de organizações mais amplas. Outras iniciativas, como o coletivo B, se afastam dos movimentos LGBTQIA+ para criar espaços independentes de ativismo bissexual.

Esse processo vai ao encontro do que sugere a literatura sobre a formação de coletivos - ou seja, como iniciativas que buscam romper com a lógica hierárquica e rígida de organizações de movimentos sociais mais formalizadas, neste caso, do movimento LGBTQIA+. Isso corrobora os argumentos de Perez (2019), para a qual os discursos dos coletivos demarcam suas diferenças com relação a partidos políticos, sindicatos, igrejas etc., sublinhando a importância da autonomia, da horizontalidade e de uma experiência organizacional menos formal e mais colaborativa. Essa autonomia em muito diz respeito à independência em relação às formas tradicionais de mobilização, participação e representação política, onde normalmente há lideranças formais, uma estrutura verticalizada e pouco espaço para tomada de decisões e exposição de ideias por parte dos sujeitos pertencentes ao grupo. 
Dessa forma, a autodeclaração como coletivo pode ser percebida como uma resposta à descrença/crítica direcionada às experiências organizacionais tradicionais (Perez, 2019). Nessa crítica, busca-se demarcar um ativismo pautado no diálogo feito coletivamente (Lima, 2018), portanto, resistente à ideia de liderança formal e formas e experiências verticalizadas de tomada de decisão do grupo. No caso aqui abordado, a autodenominação como coletivo designa certo afastamento em relação a determinadas organizações do movimento LGBTQIA+, uma vez que estas tendem a excluir e/ou deslegitimar os sujeitos bissexuais. Como um repertório organizacional alternativo, os sujeitos passaram a construir coletivamente outros espaços que se pretendem não excludentes e onde não há lideranças formais ou hierarquias, seja entre participantes seja entre identidades e práticas sexuais.

Se, de um lado, alguns grupos bissexuais e ativistas independentes incluem-se em grupos de ativismo LGBTQIA+, em um movimento centrípeto, em direção a um centro comum de identificação enquanto desvio da norma heterossexual, de outro lado, as iniciativas de organização bissexual independentes, marcadas nos coletivos, se apresentam em um movimento centrífugo, que indicam a necessidade de apontar a diferença e a especificidade da bissexualidade, que não caberia na identidade comum LGBTQIA+. Tomo emprestadas, aqui, as expressões utilizadas por Sônia Maluf (2006) em sua discussão sobre um encontro feminista, onde a reivindicação do lugar político legítimo dentro do movimento, por parte de diferentes grupos de mulheres, se dava a partir de movimentos opostos - chamados por ela de centrífugo e centrípeto. No movimento centrípeto, era preciso apontar o que era semelhante apesar das diferenças e, no movimento centrífugo, apontar a própria diferença como suporte dessa legitimidade (Maluf, 2006). No ativismo bissexual os dois movimentos se fazem presentes. De um lado, quando busca um elemento comum ao participar ou mesmo integrar organizações LGBTQIA+ mais amplas e, de outro, ao formar coletivos independentes e estabelecer pautas próprias específicas à bissexualidade.

No coletivo $\mathrm{B}$, uma das principais preocupações quanto à população bissexual diz respeito à sua saúde mental, também devido à sua exclusão de inúmeros espaços. Por esse motivo, os ativistas adotam uma estratégia que visa remediar essas exclusões, a saber, o acolhimento de pessoas bissexuais. Conforme veremos na próxima seção, a ideia de acolhimento diz respeito à construção de espaços seguros para pessoas bissexuais, com vistas ao cuidado mútuo e à sociabilidade dos participantes, para combater o sofrimento e o adoecimento mental.

A ênfase no acolhimento sinaliza um afastamento estratégico e discursivo de organizações que excluem pessoas bissexuais. Nesse sentido, além de visar o cuidado, a 
noção de acolhimento demarca a diferença entre movimentos hegemônicos com suas estruturas verticais e uma iniciativa coletivista que prioriza estratégias horizontais e dialógicas que abracem a diversidade no interior do ativismo bissexual, ao invés de reprimi-la.

Adicionalmente, o acolhimento denota a construção de laços afetivos e de identificação entre membros e participantes das ações do coletivo por meio da criação de espaços de convivência. Tais espaços permitem a formação do que Desouza (2012) chama de "ideologia coletiva", fortalecendo valores comuns e relações de lealdade entre membros. O acolhimento, portanto, diz respeito a estratégias adotadas para criar redes de sociabilidade e solidariedade para a promoção da saúde de pessoas bissexuais através do apoio mútuo.

\section{Coletivo B: um espaço de acolhimento}

A bissexualidade como identidade política vem se fortalecendo no Brasil, consolidando-se com a atuação de coletivos e ativistas autônomos. Nesse contexto, o coletivo B se mostra como um dos espaços bissexuais de maior relevância e abrangência no Brasil, especialmente na internet.

A mobilização da internet e suas tecnologias, inclusive, tem sido ressaltada pela literatura como fundamental às organizações societárias contemporâneas, uma vez que teriam assumido a função de trabalho de base por meio da ampliação das mobilizações (Cf. Maia, 2013; Gohn, 2017). Nessa linha, Gohn (2017) argumenta que as redes sociais virtuais se apresentam como a forma básica de atuação dos coletivos, por seu grande potencial de mobilização da sociedade civil.

Nos ambientes digitais criados pelo coletivo B, essa ampliação é evidente: no grupo do Facebook, milhares de bissexuais de diversas partes do país conversam, compartilham relatos de experiências, violências sofridas, dúvidas e inquietações. Percebe-se, pois, que a internet possibilita novas formas de sociabilidade e de acesso à informação (Gohn, 2017). Por meio desses espaços, potencializados pelas redes sociais online, ativistas se organizam para ações coletivas, por vezes independentes do coletivo e fora de São Paulo. O coletivo B, portanto, constrói tanto espaços físicos como digitais de ativismo; espaços também - e talvez principalmente - de sociabilidade bissexual.

Esse tipo de construção de "sociabilidade" é igualmente identificado por Desouza (2012) na ação dos coletivos. Em seu trabalho sobre coletivos feministas na Índia, a autora destaca que essas organizações construíam redes de sociabilidade entre as mulheres que as 
integravam, produzindo uma espécie de "ideologia coletiva" ${ }^{6}$ ". Um dos resultados da atuação desses coletivos, assinalado por Desouza, diz respeito ao desenvolvimento pessoal de suas membras. Nesse sentido, o empoderamento individual das mulheres participantes dos coletivos é ressaltado pela autora como um produto valioso dessas organizações, essencial para as mudanças políticas e ideológicas mais amplas que desejam desencadear. Ademais, a solidariedade entre membras dos coletivos era fortalecida pelo encorajamento à participação e ao envolvimento nas decisões coletivas - propiciando um fortalecimento individual e coletivo.

No coletivo B, as redes de sociabilidade e solidariedade são alguns dos aspectos mais importantes e valorizados por seus membros e participantes, tendo em vista que ele se propõe como um espaço de acolhimento para pessoas bissexuais. Esse acolhimento visa reverter os processos de exclusão e solidão, que dão origem a sofrimentos e ao adoecimento mental de pessoas bissexuais. Ele se constitui em uma ação direta na promoção da saúde dessa população, visando combater transtornos como a ansiedade e a depressão, além de ideações suicidas e do abuso de substâncias que possam resultar desse sofrimento.

As principais e mais frequentes ações promovidas pelo coletivo no período da pesquisa eram direcionadas ao acolhimento da população bissexual. Trata-se das Rodas de Validação de Experiências Bissexuais, mediadas por psicólogos e realizadas quinzenalmente em local público, na região central da cidade de São Paulo, aos finais de semana. Na descrição desses eventos no Facebook, argumenta-se que pessoas bissexuais "são a orientação [sexual] com maior índice de problemas de saúde mental" e que as Rodas pretendem cumprir um papel de acolhimento e validação de suas experiências. De acordo com um dos psicólogos responsáveis, elas têm o objetivo de criar conexões entre a população bissexual para que essas pessoas não se sintam sozinhas.

\footnotetext{
Chegar lá [na Roda] e falar de uma coisa que você tá passando no trabalho e outra pessoa fala "nossa, eu já passei por isso também, e eu fiz isso, isso e isso e deu certo", ou "não deu certo, não faça"; faz com que as pessoas se sintam parte de algo e que tão contribuindo pro bem estar das outras pessoas e que tão contribuindo pro próprio bem estar. E acaba sendo um aprendizado mútuo. Mas o objetivo é mais criar esses espaços seguros pra que as pessoas consigam conviver (Entrevista com psicólogo mediador da Roda, 2019).
}

\footnotetext{
${ }^{6}$ Para Desouza (2012), a "ideologia coletiva” é um dos principais componentes de um coletivo bem-sucedido, do qual derivam alguns princípios como: a existência de um conjunto de valores que orienta as atividades do grupo; a valorização dos indivíduos e da organização como igualmente importantes; e o foco na consolidação de equipes, que forma laços entre membros do coletivo e fortalece a lealdade, solidariedade e comprometimento.
} 
Durante esses encontros, os participantes relatam experiências, vivências e sentimentos, que por vezes são compartilhados por diversas pessoas no grupo. Se a bissexualidade é ininteligível a partir da matriz heterossexual (Butler, 2016), uma vez que rompe com as expectativas de coerência entre sexo, gênero e desejo, pode-se compreender que o papel do mediador das Rodas é auxiliar os participantes na elaboração das experiências, de modo a torná-las compreensíveis e inteligíveis. Assim, a existência de espaços bissexuais como o coletivo B é considerada, pelos interlocutores, importante para a "descoberta" ou “compreensão" da própria bissexualidade. Nesse sentido, eu argumentaria que, para além de acolher e validar experiências bi, esses espaços produzem bissexualidades na medida em que as tornam imagináveis. Ao mesmo tempo, criam redes de sociabilidade e apoio não só a partir do psicólogo mediador, mas também entre os participantes da Roda.

Para o ativista David, a criação de uma comunidade bissexual é importante para disponibilizar informações a respeito da bissexualidade, pansexualidade e outras formas de monodissidência. Isso atenuaria a sensação de dúvida e confusão, que causa sofrimento para essas pessoas:

Pra mim o objetivo mais claro é unir as pessoas pra que eles conheçam a bissexualidade, sintam que é uma opção viável pra se descreverem. [...] Pra mim, mas eu acho que é muito pessoal, o B veio nesse sentido. [...] Então cada um tem suas lutas pessoais, mas que acaba entrando muito disso de proteger as pessoas bissexuais, conseguir trazer algum alento pra elas porque a gente já sofre tanto no dia-a-dia e talvez ajudar os outros faça doer um pouco menos, digamos (Entrevista com David, 2019).

Conforme mencionado, uma das principais pautas do coletivo tem relação com o sofrimento relatado por pessoas bissexuais. Os ativistas argumentam que, tratando-se de orientação sexual, bissexuais compõem a população com maior taxa de suicídio e maior vulnerabilidade à depressão. Em uma carta de reivindicações à Câmara Municipal de São Paulo, em 2017, o coletivo argumenta que há poucos dados estatísticos a respeito da população monodissidente no Brasil, mas que seria possível utilizar dados estrangeiros que retratam situações semelhantes às observadas nos espaços de militância e convivência bissexual: de maior vulnerabilidade em saúde mental ${ }^{7}$.

No Brasil, pesquisas sobre a saúde da população bissexual são escassas, mas existem alguns dados que indicam que os problemas identificados em outros países também podem ocorrer aqui. Um exemplo é a pesquisa de Fernando Teixeira-Filho e Carina Rondini (2012) com adolescentes entre doze e vinte anos do interior de São Paulo. A pesquisa aponta que os

\footnotetext{
${ }^{7}$ Para uma revisão de pesquisas que apresentam esses dados, ver Leão (2018) e Eisner (2013).
} 
adolescentes não-heterossexuais têm aproximadamente o dobro de chances de pensar em suicídio e o triplo de chances de tentá-lo, em comparação com seus pares heterossexuais. Entre os não-heterossexuais, os adolescentes que se identificaram na pesquisa como "bissexuais" ou "outros" mostraram-se os mais vulneráveis, tanto a tentativas quanto a pensamentos suicidas.

Ativistas bissexuais utilizam dados semelhantes para defender a criação de políticas públicas de prevenção ao suicídio e atendimento psicológico a pessoas bissexuais, apontando para o despreparo de profissionais para lidar com questões de saúde mental com pacientes bissexuais. Para Stephanie, os problemas de saúde mental decorrem da invalidação sofrida por bissexuais:

\begin{abstract}
A gente tem as piores estatísticas dentro das orientações sexuais. [...] Porque a gente é invalidado o tempo inteiro, né? É uma vida inteira ouvindo outras pessoas dizerem que elas sabem mais sobre a sua sexualidade, sobre a sua afetividade do que você. [...] Eu acho que isso é uma coisa que acaba muito com a nossa saúde mental, você ser invalidado em todos os espaços. Tudo que você fala as pessoas [dizem] "não, você tá errado". Sabe, "não, não acredito em você". Teve um negócio que eu li uma vez que falava que a homofobia e a lesbofobia falava pros gays e lésbicas: "o jeito que você ama tá errado, o jeito que você ama é pecado" e tal. E a bifobia fala pra pessoas bissexuais: "você não ama". Sabe, "eu não consigo conceber a forma como você ama. Isso é uma impossibilidade". [...] E o fato de que quando a gente se entende como não hétero e a gente começa a procurar os espaços LGBT e a gente acha que vai ser acolhido e a gente em geral encontra bifobia a rodo, sabe. É mais invalidação, é mais deslegitimação. Eu acho que isso também tem um impacto muito grande na saúde mental. Você achar que você vai ser acolhido num espaço e você apanhar de novo, sabe. Isso é muito complicado (Entrevista com Stephanie, 2019).
\end{abstract}

Como fica explícito na fala de Stephanie, para os ativistas, esse sofrimento seria causado pelas violências e recusas sofridas por bissexuais, inclusive ao tentarem buscar acolhimento em espaços LGBTQIA+. Nesse sentido, pessoas bissexuais teriam em comum um sentimento de solidão por, ao mesmo tempo, fugirem à heteronorma e não serem aceitas em espaços ditos LGBTQIA+.

É possível entender a argumentação dos ativistas sobre o sofrimento bissexual como uma política de biolegitimidade, ou seja, o uso do corpo em sofrimento como um recurso para reivindicação de direitos. De acordo com Fassin (2012), os sentimentos morais ocupam um lugar central nas políticas contemporâneas direcionadas aos necessitados e dominados a partir do sofrimento e da compaixão, ou seja, das emoções em relação aos infortúnios desses dominados e a vontade de corrigi-los (Fassin, 2012). As vidas precárias, as pessoas em sofrimento, seriam o objeto do que Fassin (2012) chama de governo humanitário, a saber, dos sentimentos morais na política. Nesse sentido, faz-se necessário, para o coletivo B, construir as pessoas bissexuais como vítimas - a partir da mobilização de pesquisas e de dados 
estatísticos sobre seu sofrimento - para reivindicar políticas públicas voltadas à saúde e ao reconhecimento da população bissexual.

As demandas do coletivo dizem respeito principalmente à formação de profissionais e agentes de saúde - em especial da psicologia e ginecologia - voltada para o atendimento de pessoas bissexuais e suas necessidades, uma vez que, de acordo com os ativistas, estes profissionais são comumente despreparados para lidar com essa população e, consequentemente, podem agravar problemas psicológicos já existentes ou negligenciar a saúde sexual de pessoas bissexuais que buscam atendimento. Além disso, os ativistas reivindicam a inclusão de bissexuais em cartilhas de saúde e em estratégias de prevenção a Infecções Sexualmente Transmissíveis (IST), as quais não costumam contemplar sujeitos que mantém relações sexuais com pessoas de diferentes gêneros e suas especificidades no que concerne à saúde sexual e reprodutiva.

Tendo em vista o sofrimento mental relatado por pessoas bissexuais, um dos objetivos do coletivo B é acolher pessoas monodissidentes e construir uma comunidade bissexual para que as pessoas não se sintam tão sozinhas. Os ativistas ressaltam a importância de criar espaços bissexuais, já que eles seriam muito raros ou inexistentes. Questionada a respeito dos objetivos do coletivo, uma ativista respondeu:

Eu acho que principalmente a questão de criar comunidade, sabe. Porque a gente é muito isolado. Aquele clichê, mas é verdade, a gente não tá totalmente em casa nem no meio mainstream nem no meio que se diz LGBT. Então a gente tem que criar nossos próprios espaços (Entrevista com Stephanie, 2019).

Algumas pessoas me relataram que o interesse nos espaços do coletivo B se fundou na necessidade de uma comunidade, de conhecer pessoas com quem pudessem compartilhar experiências. Outras contam que o B foi muito importante em suas trajetórias e no entendimento de sua bissexualidade, porque reunia informações a esse respeito, que não eram encontradas em outro lugar. Isso demonstra a importância dos laços de sociabilidade e solidariedade construídas nos espaços do coletivo, conforme demonstrado também por Desouza (2012).

Nesse contexto, a coletividade bissexual, criada pelo coletivo B, é vista pelos interlocutores como essencial para vivenciar a própria bissexualidade e para combater o sofrimento ou preservar sua saúde mental. Isso porque, estando excluída do binômio heterossexual/homossexual, a bissexualidade não é vista como uma possibilidade de existência inteligível. 
Ao narrar ${ }^{8}$ seus processos de entendimento da própria sexualidade, os interlocutores da pesquisa relataram que há um período de confusão, de dúvida, por não se entenderem ou não saberem como se identificar. Os rótulos disponíveis - gay, lésbica ou heterossexual - não davam conta de explicar suas experiências, que incluíam a atração romântica ou sexual por pessoas de diferentes gêneros. É a partir do contato com outras pessoas bissexuais ou com informações a respeito da bissexualidade que os sujeitos da pesquisa visualizam a possibilidade de compreender sua experiência.

O processo de adoção de uma identidade ou de práticas bissexuais é comumente narrado pelos interlocutores da pesquisa como uma "descoberta", seja da sexualidade ou de palavras para descrevê-la. Essa noção de descoberta é particularmente reveladora de uma visão que alguns ativistas têm da bissexualidade, isto é, como algo pré-discursivo, que existia enquanto essência ou potência antes de ser conhecido. O período que antecede essa "descoberta" é marcado, em suas narrativas, por dúvidas e processos de invalidação por terceiros, passando por uma dificuldade de definição relacionada à sexualidade.

Aqui, o coletivo B tem um papel importante: frequentemente, é por meio dele que essas pessoas dizem conhecer a bissexualidade como uma possibilidade válida e legítima para interpretar e nomear suas experiências. Nas narrativas individuais, portanto, o coletivo aparece como um ponto importante no processo de aceitação da própria sexualidade, essencial para combater sentimentos de dúvida, confusão e sofrimento causados pela invalidação da bissexualidade. É comum que os espaços virtuais criados pelo coletivo B tenham um papel central nessas narrativas de descoberta e identificação. A fala do ativista David ilustra essa situação:

\begin{abstract}
Quando eu li um texto do B lá quando eu tava me descobrindo bi e era uma pessoa falando o que ela sentia enquanto pessoa bissexual. E eu fui lendo aquilo e falando assim "nossa, eu passo por isso. Eu passo por isso. Eu passo por isso. Eu passo por isso". Quando eu dei check no texto inteiro eu comecei a chorar. Porque eu falei "nossa, agora tudo faz sentido. É essa palavra que me define". E não definir no sentido de limitar, mas eu consigo explicar o que eu sinto e tem mais gente que sente a mesma coisa que eu, eu não sou algo estranho fora da caixa que não sabe seu lugar (Entrevista com David, 2019).
\end{abstract}

O sofrimento relacionado a situações de bifobia é relatado pelos ativistas como algo constante e permanente. Entretanto, os sujeitos da pesquisa relatam que a angústia de não saber se definir tem fim quando encontram narrativas semelhantes à sua experiência, como na fala do ativista Agenor:

\footnotetext{
${ }^{8}$ Entendo as narrativas, conforme Sônia Maluf (1999), como formas de interpretar e dar sentido às experiências vividas.
} 


\begin{abstract}
Acho que qualquer tipo de identidade, eu acho que você conhecer, ter contato com outras pessoas que se identificam como você, te ajudam a te fortalecer sua identidade. Te dão uma sensação de conforto, você ter essas pessoas ao seu lado te dão uma sensação de pertencimento. Eu acho que isso é uma das coisas mais importantes: você se sentir pertencente a um lugar onde você tá (Entrevista com Agenor, 2019).
\end{abstract}

As falas de David e Agenor mostram que a partir do contato e convívio com outras pessoas bi, a bissexualidade passa a ser uma narrativa possível, reconhecível e válida. Outro interlocutor, Fred, comenta também que foi por meio do B que começou a aprender sobre sexualidade e gênero. Ele relata que antes não conseguia se entender, mas a partir do contato com o coletivo passou a se identificar como pansexual. Nesse sentido, pode-se dizer que o coletivo B age não apenas como um agregador de pessoas bissexuais, mas também como um agente formador de (bi)sexualidades. Ao contrário de ativistas e coletivos bissexuais que buscam a inclusão em espaços gays, lésbicos ou LGBTQIA+, como no caso descrito por Leão (2018), o coletivo B tem o objetivo de construir espaços especificamente bissexuais, que não têm como intenção principal se voltar ao movimento LGBTQIA+ - embora o coletivo estabeleça alianças estratégicas e temporárias, em meio a conflitos, como é o caso da participação dos ativistas nas Paradas. O formato horizontal e plural de coletivo é um meio utilizado pelos ativistas para evitar e combater opressões no interior dos espaços criados por eles, de modo a cumprir seu papel de acolhimento às pessoas bissexuais e de promoção da saúde mental. As decisões e ações são tomadas coletivamente, dando espaço no interior do grupo a diferentes perspectivas e narrativas, especialmente o que diz respeito às diversidades étnico-raciais, de gênero, deficiência, entre outras. Isso se reflete também na postura feminista, antirracista, antifascista, anticapacitista e aliada às pautas trans e assexuais que o coletivo defende.

A partir do acolhimento e do compartilhamento de narrativas sobre bissexualidade e monodissidências, o coletivo produz uma visibilidade bissexual internamente, que possibilita, a seus participantes reconhecer e legitimar identidades e práticas repudiadas em outros espaços. Ao invés de demandar uma visibilidade e reconhecimento das pautas bissexuais junto aos movimentos LGBTQIA+, o coletivo produz um espaço independente, onde a bissexualidade se torna visível por meio de seu protagonismo em um ativismo bissexual autônomo. Além do mais, este espaço passa a acolher pessoas bissexuais que seriam rejeitadas em espaços LGBTQIA+ mais amplos, atuando como rede de apoio e sociabilidade para pessoas bissexuais que venham a desenvolver adoecimentos psíquicos causados por essa rejeição, mas que não encontram, nos agentes de saúde, o devido apoio. 
Assim, o acolhimento como ativismo aparece como uma estratégia de combate a esse sofrimento causado por violências e exclusões sofridas por bissexuais, tanto pela heteronorma quanto em espaços ditos LGBTQIA+. É uma ação objetiva do coletivo com vistas a auxiliar essa população e proporcionar um convívio entre pessoas bissexuais que possibilite uma vivência sadia da bissexualidade, baseada no apoio mútuo. Desouza (2012) argumenta que, mesmo se um coletivo não exerce grande influência política ou não tenha alcançado grandes objetivos, ele ainda pode ser entendido como eficiente e bem-sucedido se considerarmos o desenvolvimento pessoal de suas participantes. Nessa perspectiva, o coletivo B pode ser caracterizado como bem-sucedido na promoção da saúde e da autoestima de pessoas bissexuais por intermédio da criação de espaços de sociabilidade que permitem o apoio mútuo e a validação de suas experiências, uma vez que os ativistas entrevistados frisam a importância desses espaços nas suas narrativas pessoais de "descoberta".

\section{Considerações finais}

A bissexualidade é colocada em uma posição ambivalente com os movimentos LGBTQIA+, por ser, ao mesmo tempo, incluída (ao menos nominalmente) e excluída deles pelo que Lewis (2012) chama de matriz homonormativa. Assim, as pautas defendidas pelos movimentos LGBTQIA+ hegemônicos não refletem as demandas de ativistas bissexuais que, adicionalmente, relatam sofrer bifobia em tais espaços. Nesse contexto, o coletivo B se afasta desses movimentos LGBTQIA+ ao afirmar que possui especificidades e diferenças e ao buscar construir um espaço próprio que reúna pessoas com experiências semelhantes a partir da chave da bissexualidade ou monodissidência.

De acordo com os ativistas, as violências que os vitimizam nos mais diferentes espaços fazem com que bissexuais tenham um sofrimento aprofundado, necessitando de políticas públicas que visem seu atendimento psicológico. Por esse motivo, parte significativa da atuação do coletivo $\mathrm{B}$ tem relação com a questão do sofrimento bissexual, seja reivindicando políticas públicas seja tentando mitigar o problema da solidão, criando espaços de sociabilidade.

Nas narrativas individuais, o sofrimento se faz presente principalmente no que diz respeito à confusão e à solidão que os sujeitos da pesquisa afirmam sentir antes do que chamam de "descoberta da bissexualidade". Aqui, uma coletividade bissexual é vista pelos interlocutores como essencial para a "descoberta da bissexualidade" e para preservar sua 
saúde mental. Assim, o coletivo B se coloca como um agente central na formação de uma coletividade bissexual que dá sustentação às identidades bissexuais individuais.

Conforme procurei demonstrar, a principal forma de ativismo empregada pelo coletivo B diz respeito ao acolhimento de pessoas bissexuais e monodissidentes. Esse acolhimento se materializa na criação de espaços de sociabilidade e solidariedade, onde a bissexualidade é validada e normalizada, em especial nas Rodas de Validação de Experiências Bissexuais. Essas iniciativas buscam combater o sofrimento e o adoecimento específico que acomete pessoas bissexuais devido à sua rejeição em diversos espaços. Trata-se, portanto, de uma ação direta de atenção à saúde mental dessa população, uma vez que não há atendimento especializado disponível para ela junto aos profissionais de saúde.

A caracterização do acolhimento como ativismo auxilia na compreensão dos laços de solidariedade criados em organizações caracterizadas como coletivos, lançando luz sobre uma forma de ativismo pautada no apoio mútuo. Trata-se de uma forma de ativismo independente, que tem como objetivo atender diretamente as demandas da população à qual se destina, auxiliando sujeitos em situação de sofrimento e adoecimento mental. Para além de demandar políticas públicas, portanto, o coletivo B se coloca como um agente de cuidado e promoção de saúde.

Ademais, este artigo buscou contribuir para o campo de estudos dos coletivos ao tratar de uma temática ainda pouco explorada na literatura - isto é, o ativismo bissexual, que atua no Brasil principalmente por meio de coletivos. No entanto, são necessárias pesquisas adicionais para compreender como os demais coletivos bissexuais têm atuado no país, bem como outras manifestações do que chamei aqui de acolhimento como ativismo.

\section{Referências}

ANGELIDES, Steven (2001), A history of bisexuality. Chicago, The University of Chicago Press.

AULT, Amber (2002), “Amber Ault: Ambiguous Identity in an Unambiguous Sex/Gender Structure: The Case of Bisexual Women (1996)", in M. Storr, Bisexuality: A Critical Reader. Ebook, Taylor \& Francis E-library.

BORDT, Rebecca L. (1997), "How alternative ideas become institutions: the case of feminist collectives". Nonprofit and Voluntary Sector Quarterly, v. 26, n. 2, pp. 132-55 [Consult. 27-102020]. Disponível em https://doi.org/10.1177/0899764097262003

BUTLER, Judith (2016), Problemas de gênero: feminismo e subversão da identidade. Rio de Janeiro, Civilização Brasileira. 
CALLIS, April S. (2009), "Playing with Butler and Foucault: Bisexuality and Queer Theory". Journal of Bisexuality, vol. 9, n. 3-4, pp. 213-233 [Consult. 27-10-2020]. Disponível em https://www.tandfonline.com/doi/full/10.1080/15299710903316513

CAVALCANTI, Camila D. (2010), "Práticas bissexuais: uma nova identidade ou uma nova diferença?" Polêm!ca, v. 9, n. 1, pp. 79-83 [Consult. 27-10-2020]. Disponível em https://www.epublicacoes.uerj.br/index.php/polemica/article/view/2710/1858

(2007), Visíveis e invisíveis: práticas e identidade bissexual. Dissertação (Mestrado em Sociologia) - Curso de Sociologia, Centro de Ciências Humanas e Filosofia, Universidade Federal de Pernambuco, Recife. 112p.

DESCHAMPS, Catherine (2008), "Visual Scripts and Power Struggles: Bisexuality and Visibility". Journal of Bisexuality, v. 8, n. 1-2, pp. 131-139 [Consult. 27-10-2020]. Disponível em https://www.tandfonline.com/doi/full/10.1080/15299710802142895?scroll=top\&needAccess=true

DESOUZA, Shaila (2012), "The Strength of Collective Processes: An "Outcome Analysis" of Women's Collectives in India”. Indian Journal of Gender Studies, v. 19, n. 3, pp. 373-92 [Consult. 27-10-2020]. Disponível em https://journals.sagepub.com/doi/10.1177/097152151201900302

DOMÍNGUEZ RUIZ, Ignacio E. (2017), Bifobia: etnografía de la bisexualidad en el activismo LGTB. Barcelona/Madrid, Editorial Egales.

EISNER, Shiri (2013). Bi: notes for a bisexual revolution. Berkeley, Seal Press.

FACCHINI, Regina (2002), "Sopa de Letrinhas"? Movimento homossexual e produção de identidades coletivas nos anos 90: um estudo a partir da cidade de São Paulo. Dissertação (Mestrado em Antropologia) Departamento de Antropologia, IFCH, UNICAMP, Campinas, SP.

FASSIN, Didier (2012), Humanitarian Reason: a moral history of the present. Berkeley, University of California Press.

GOHN, Maria da G. (2017), Manifestações e protestos no Brasil: correntes e contracorrentes na atualidade. São Paulo, Cortez.

KAUFMANN, Jean-Claude (2013), A entrevista compreensiva: um guia para pesquisa de campo. Rio de Janeiro, Editora Vozes.

LEÃO, Maria (2018), Os unicórnios no fim do arco-íris: bissexualidade feminina, identidades e política no Seminário Nacional de Lésbicas e Mulheres Bissexuais. Dissertação (Mestrado em Saúde Coletiva), Universidade do Estado do Rio de Janeiro, Rio de Janeiro. 119 p.

LEWIS, Elizabeth S. (2012), "Não é uma fase": Construções identitárias em narrativas de ativistas LGBT que se identificam como bissexuais. Dissertação (Mestrado em Letras), Departamento de Letras, Pontifícia Universidade Católica do Rio de Janeiro, Rio de Janeiro. 267 p.

LIMA, Stephanie (2018), “'Coletivo', 'ativista' e 'horizontal': uma análise de categorias em uso no movimento social contemporâneo". Teoria e Cultura, v. 13, n. 1, pp. 18-34 [Consult. 27-10-2020]. Disponível em https://periodicos.ufjf.br/index.php/TeoriaeCultura/article/view/12382

MAÇÃO, Izabel R. (2017), "Bissexualidade: práticas, enunciados e resistências", in A. Silva; J. Oliveira; L. Oliveira; P. Queiroz (Orgs.), Escola e Liberdade. 1. ed. Vila Velha, Praia, pp. 121-134.

MAIA, Gretha L. (2013), "A juventude e os coletivos: como se articulam novas formas de expressão política". Revista Eletrônica do Curso de Direito da UFSM, v. 8, n. 1, pp. 58-73 [Consult. 27-102020]. Disponível em https://periodicos.ufsm.br/revistadireito/article/view/8630/pdf 
MALUF, Sônia W. (2006), Políticas e teorias do sujeito no feminismo contemporâneo. Anais do Seminário Internacional Fazendo Gênero 7, Santa Catarina. (1999), "Antropologia, narrativas e a busca de sentido", Horizontes antropológicos, Porto Alegre, v. 5, n. 12, pp. 69-82 [Consult. 27-10-2020]. Disponível em https://www.scielo.br/pdf/ha/v5n12/0104-7183-ha-5-12-0069.pdf

PEREZ, Olívia C. (2019), "Relações entre coletivos com as Jornadas de Junho". Opinião Pública, Campinas, v. 25, n. 3, pp. 577-596 [Consult. 27-10-2020]. Disponível em https://www.scielo.br/pdf/op/v25n3/1807-0191-op-25-3-0577.pdf

PEREZ, Olívia C.; SILVA FILHO, Alberto L. A. (2017), "Coletivos: um balanço da literatura sobre as novas formas de mobilização da sociedade civil”. Latitude, v. 11, n. 1, pp. 255-94 [Consult. 27-102020]. Disponível em http://www.seer.ufal.br/index.php/latitude/article/view/2812/pdf_1

SEFFNER, Fernando (2003), Derivas da masculinidade: Representação, identidade e diferença no âmbito da masculinidade bissexual. Tese (Doutorado em Educação), Faculdade de Educação, Universidade Federal do Rio Grande do Sul, Porto Alegre. 261 p.

STORR, Merl (2002), Bisexuality: a critical reader. Ebook, Taylor \& Francis E-library.

TEIXEIRA-FILHO, Fernando S.; RONDINI, Carina A. (2012), "Ideações e tentativas de suicídio em adolescentes com práticas sexuais hetero e homoeróticas". Saúde e Sociedade. São Paulo, v. 21, n.3, pp. 651-667. Disponível em https://www.scielo.br/pdf/sausoc/v21n3/11.pdf [Consult. 27-102020]. 


\begin{abstract}
The object of this article is the performance of a bisexual collective in Sao Paulo city, intending to explore bisexuality as a political organization, especially regarding the creation of welcoming spaces for bisexuals. The research was conducted through semi-structured interviews with twelve activists, as well as participant observation in one activity and analyses of documents published by the collective. It was found that the collective adopts a policy of biolegitimacy by claiming rights to bisexual people through the affirmation of the existence of a kind of suffering originated in biphobia which victimizes them. In their individual narratives, the interlocutors use the notion of a "discovery of bisexuality", in which finding welcoming in a bisexual community appears as a fundamental factor for the construction of bisexual identity and the fight against psychological suffering.
\end{abstract}

Keywords: Bisexuality; Monodissidence; Activism; LGBTQIA+ Movements.

\title{
Resumen
}

Este artículo tiene como objeto la actuación de un colectivo bisexual en la ciudad de São Paulo, con el objetivo de explorar la bisexualidad como organización política, especialmente en lo que respecta a la creación de espacios de acogida. La investigación se realizó a través de entrevistas semiestructuradas con doce activistas, además de la observación participante en una actividad presencial y el análisis de documentos publicados por el colectivo. Se constató que el colectivo adopta una política de biolegitimidad en la medida en que reivindica derechos a las personas bisexuales afirmando la existencia de un sufrimiento que se originaría en la bifobia que las victimiza. A su vez, en las narrativas individuales, los interlocutores utilizan la noción de "descubrimiento de la bisexualidad", donde encontrar acogida de una comunidad bisexual aparece como factor fundamental para la construcción de una identidad bisexual y la lucha contra el sufrimiento psicológico.

Palabras clave: Bisexualidad; Monodisidencia; Activismo; Movimientos LGBTQIA+. 